\title{
Phenotypic and Molecular Characterization of Pathogenic Bacteria Isolated from Commercialised Herbal Products in
}

\section{Kenya}

\author{
Onyambu $\mathrm{MO}^{1 *}$, Kahiga T1 , Muturi $\mathrm{M}^{2}$ and Nyamari JM${ }^{3}$ \\ ${ }^{1}$ Department of Pharmacy and Complementary/Alternative Medicine, Kenyatta \\ University, Kenya \\ ${ }^{2}$ Department of Medical Laboratory Science, Kenyatta University, Kenya \\ ${ }^{3}$ Department of Environmental health, Kenyatta University, Kenya
}

\section{Research Article \\ Volume 2 Issue 2}

Received Date: February 07, 2018

Published Date: March 22, 2018

*Corresponding author: Meshack O Onyambu, Department of Pharmacy and Complementary/Alternative Medicine, School of Medicine, Kenyatta University, Nairobi, Kenya, 43844-0100, Tel: +254726099487; Email: onyambu.meshack@ku.ac.ke

\section{Abstract}

Background: The widespread use of herbal medicine has led to its approval by World Health Organization (WHO) as a factor in the attainment of universal health care coverage together with conventional medicine. However, unlike conventional medicine, herbal medicine has many challenges yet to be addressed. Pathogenic microbial contamination has been cited as a serious quality issue in previous studies done in Kenya and other countries with no regulation of herbal medicines. Despite newer techniques of microbial analysis taking shape in routine microbial identification and characterization, quality control laboratories use pharmacopoeal techniques to address the same microorganisms without due regard to possible newer contaminants which may not be detected by the traditional routinely used techniques.

Objective: This study was designed to use genotypic techniques not utilized before in quality control laboratories for microbial contaminant determination in herbal and nonsterile pharmaceuticals.

Materials and Methods: 16SrRNA a unique conserved gene to bacteria was used to identify bacteria that could not be detected by routine methods. Bacterial contaminants were isolated from thirty samples of registered and nonregistered herbal products collected by random purposive sampling from five regions in Kenya. Identification of the unknown isolates was done first by use of selective and differential media as per the British Pharmacopoeia 2007; Biochemical identification was done by API 20E commercial kit according to the manufacturer's instructions. Molecular characterization by DNA fingerprinting, sequencing and phylogenetic analysis was done for the unknown contaminants.

Results: Nineteen (19) bacteria were characterized from all the samples. Thirteen isolates were identified by the phenotypic methods while the rest would only be characterized by the molecular methods. 
Conclusion: This study showed that by using molecular techniques, herbal products may contain bacterial contaminants that are not included in the Pharmacopoeal lists.

Keywords: Pathogenic Bacteria; Herbal Products; Pharmacopoeal Techniques

\section{Introduction}

Globally, there is continued increase in demand for traditional medicine with over $70 \%$ of the world population particularly in developing countries relying mainly on herbal medicines for their primary health care [1]. This is because herbal medicines are accessible and cheap. Given the affordability, accessibility and popularity, WHO, [2] has identified herbal medicine as a factor in the attainment of universal health coverage with the objective of providing the highest attainable standard of health. Inspite of the many social and economic issues serving as incentives for the widespread use of herbal medicines, increase in the global burden of chronic disease has been cited as the most urgent reason for developing and strengthening the use of herbal medicines together with conventional medicine [3]. However, unlike conventional medicine, challenges in policies, laws and regulation, quality, safety monitoring and effective use of herbal medicines are yet to be addressed in many countries. According to WHO, [4] quality of herbal drugs is the basis of reproducible efficacy and safety thereby ensuring standardization. The WHO, [5] alludes to the hazards in herbal medicines posed by the presence of microbial contaminants and residues leading to compromised quality. Presence of serious pathogenic bacteria including Salmonella spp, Escherichia coli, Staphylococcus aureus, Shigella spp among others have been found in herbal medicines sold for therapeutic purposes in Kenya and Nigeria [6,7]. These harmful bacteria can contaminate raw materials, production facilities and package products. However, methods and techniques that can exhaustively evaluate microbial quality of herbal medicines is an area that has not been well researched especially in Africa where these issues are common.

Three major tests specific to microbial contaminants currently used are; qualitative tests for the determination of the presence or absence of any viable microorganism in a sample, quantitative tests for enumeration of microorganisms and identification tests for specified microbes [8-10,5]. However, the described tests are limited only to identification of specified species of bacteria and fungi in a given sample. This leaves a vacuum in the identification of unknown microbial contaminants which in most cases may be present but are rarely noticed. This study therefore used molecular techniques not previously utilized in herbal medicine to identify contaminants that could not be easily characterized by routine and or traditional methods. Bacterial 16SrRNA gene from bacteria isolated in herbal medicines sold in Kenyan supermarkets, herbal clinics, streets and chemists was used in identifying bacteria that would not otherwise be identified by the morphological, biochemical or phenotypic techniques used in routine microbial analysis laboratories. This is the first study that explores the use of genotypic methods in identifying bacteria isolated from herbal products used therapeutically.

\section{Materials and Methods}

\section{Study Area and Sampling}

Bacterial contaminants were isolated from herbal samples collected by random purposive sampling from five regions in Kenya namely Central, Rift valley, Nairobi, Western and Coastal areas. The regions were identified and selected based on data obtained from the school of pharmacy, University of Nairobi for herbalists who were practicing in different regions of Kenya. Those enlisted from the regions had brought their products for scientific verification and subsequently registered as practitioners by the Ministry of Sports, Culture and Art. Thirty products, both liquid and powdered formulations were sampled as previously described by Onyambu, et al. [7].

\section{Isolation}

Pure colonies were isolated from sample cultures based on morphologic differences in form, elevation, color and size. They were labeled for easy identification and subcultured in Petri dishes divided into quadrants by streak plate technique. The plates were incubated at $37^{\circ} \mathrm{C}$ for $48 \mathrm{~h}$ in a Wolf laboratory ltd (WTB) binder incubator (Wolf laboratory ltd Poclinton, UK). The unknown isolates were kept under glycerol and nutrient agar in the ratio 70:30, in $1.5 \mathrm{~mm}$ Eppendorf tubes as stock solutions for subsequent identifications under freezer at $-23{ }^{\circ} \mathrm{C}$. Microbial viability tests were done before any experimental process with the isolates. 


\section{Phenotypic Identification}

Morphologic characterization of bacteria colonies was done by observations of form, elevation, pigmentation, size and texture. Gram staining was done as described by Preston and Morel [11] and observations made under a microscope in an oil immersion objective lens. The isolates were tested for the presence of specific bacteria (Klebsiella pneumonia, Staphylococcus aureus, Escherichia coli, Pseudomonas aeruginosa, Shigella spp. Salmonella spp., Enterobacter aerogenes) using differential and selective media as described by the British Pharmacopeia [8]. Gram negative isolates were further subjected to biochemical characterization as described by Holt et al using Analytical Profile Index (API) strip 20 E kit [12]. Identification was done with the analytical profile by numerical list comparison obtained from Kenya Medical Research Institute Center for Microbiology Research Nairobi, Kenya.

\section{Molecular Identification}

The method comprised of DNA extraction, PCR based Fingerprinting and sequencing.

DNA Extraction: DNA extraction from bacterial cultures was done using the QIAamp DNA mini kit. Following the manufacturers' instructions, isolates were suspended in $180 \mu \mathrm{l}$ of the enzyme solution $(20 \mathrm{mg} / \mathrm{ml}$ lysozyme or $200 \mu \mathrm{g} / \mathrm{ml}$ lysostaphin; $20 \mathrm{mM}$ Tris.HCL, pH $8.0 ; 2 \mathrm{mM}$ EDTA; $1.2 \%$ Triton), incubated for $30 \mathrm{~min}$ at $37^{\circ} \mathrm{C}$ then adding $20 \mu \mathrm{l}$ proteinase $\mathrm{K}$ and $200 \mu \mathrm{l}$ buffer AL before mixing thoroughly by vortexing. Further incubation was done at $56^{\circ} \mathrm{C}$ for $30 \mathrm{~min}$ followed by $15 \mathrm{~min}$ at $95^{\circ} \mathrm{C}$. The preparation was homogenized by centrifuging for $30 \mathrm{~min}$ in $100 \mu \mathrm{l}$ ATL buffer. Quantification was done by Nanodrop 2000C Spectrophotometer (Thermo Scientific Inc., Wilmington, USA) to determine the concentration of the isolated DNA.

PCR-based Fingerprinting: The experiment was performed in a final volume of 50ul with a $10 \times$ PCR buffer, dNTP mix, $25 \mathrm{mM} \mathrm{Mgcl}_{2}$, primer solutions F27 and R1525 thawed at room temperature and placed on ice. A master mix was then prepared as shown in Table 1. A thermal cycler (Gene Amp PCR systems 9700, Applied Biosystems USA) was used to amplify the bacterial genome as programmed in Table 2 in 30 cycles.

Agarose gel $(1 \%)$ was prepared by suspending $1 \mathrm{~g}$ of agarose gel in $100 \mathrm{ml}$ of TAE buffer (prepared as outlined in reagent preparation). It was heated to boil then left to cool up to $60^{\circ} \mathrm{C}$ and cast after adding $1 \mathrm{ul}$ of Ethidium bromide. After gelling (solidifying), it was slowly positioned in the electrophoresis chamber which was then flooded with a $1 \times$ TAE buffer. One (1) ul of a 10× loading dye was then carefully pipetted to the wells after removing the comb and then starting by loading a $1 \mathrm{~kb}$ ladder which was the standard, $1 \mu \mathrm{l}$ of each sample was loaded to the wells. The gel was then left to run at 100 volts (Bio-Rad, power Pac basic USA) for $30 \mathrm{~min}$ after which it was visualized under the UV (Alpha Imager, South Africa).

\begin{tabular}{|c|c|c|}
\hline Component & $\begin{array}{c}\text { Volume/reaction } \\
\text { in } \boldsymbol{\mu l}\end{array}$ & Final $\times \mathbf{1 0}$ \\
\hline $\mathrm{H}_{2} 0$ (nuclease free) & 34.75 & $340 \mu \mathrm{l}$ \\
\hline Buffer & 5 & $50 \mu \mathrm{l}$ \\
\hline $\mathrm{Mgcl}_{2}$ & 2 & $20 \mu \mathrm{l}$ \\
\hline $\mathrm{dNTPs}$ & 1 & $10 \mu \mathrm{l}$ \\
\hline Taq polymerase & 0.25 & $2.5 \mu \mathrm{l}$ \\
\hline Primer F27 & 2.5 & $25 \mu \mathrm{l}$ \\
\hline Primer R 1525 & 2.5 & $25 \mu \mathrm{l}$ \\
\hline
\end{tabular}

Table 1: PCR master mix.

\begin{tabular}{|c|c|c|c|}
\hline Step & $\begin{array}{c}\text { Temperature } \\
\left({ }^{\circ} \mathbf{C}\right)\end{array}$ & Process & Duration \\
\hline 1 & 95 & Initial denaturation & 3 min \\
\hline 2 & 95 & Denaturation & 30 secs \\
\hline 3 & 53 & Annealing & 30 secs \\
\hline 4 & 72 & Extension & 1 min \\
\hline 5 & 72 & Final extension & 7 min \\
\hline 6 & 4 & hold & Hold \\
\hline
\end{tabular}

Table 2: Thermo cycler programming.

DNA purification for sequencing: Cleaning and purification of DNA fragments from PCR was done using the QIAqick PCR Purification Kit protocol. As instructed by manufacturer, the purified DNA was then analyzed on a agarose gel by adding $6 \mu \mathrm{l}$ of the loading dye to $20 \mu \mathrm{l}$ of the purified DNA. The solution was then mixed by pipetting up and down before loading the gel. The loading dye used had 3 marker dyes (Bromophenol blue, xylene cyanol and orange G) that facilitate estimation of DNA migration distance and optimization of the gel run time.

Sequence determination: In order to determine the nucleotide sequences of the unknown bacteria, Primers used were complementary to the sequence on both sides of the segments that were amplified. The Forward primer F27 (5'-AGA GTT TGA TCM TGG CTC AG-3') and Reverse primer R1492 (5'-TAC GGY TAC CTT GTT ACG ACT T-3') were also used for sequencing. They gave gene fragments of various sizes from each template. Each gene sequence fragment was used to assemble a single sequence contigue using the contig assembly program (CAP) of the BioEdith suite [13]. 
Phylogenetic analysis: The sequences closely related to each of the isolates were fetched from the database and used to perform a multiple sequence alignment using the program MUSLE 3.6 [14]. The multiple sequence alignment was used to construct a phylogenetic tree to show evolutionary relations of the microbes using MEGA 3 software [15].

\section{Results}

\section{Phenotypic Characterization}

Gram staining and microscopy of all bacterial isolates showed a total of 19 different species, of which 13 (68\%) were Gram-negative rods while 6 (32\%) were Grampositive rods and cocci.

\section{Biochemical Characterization by differential, Selective Media and API $20 \mathrm{E}$}

Six bacterial isolates were characterized by differential and selective media with growth in Mannitol salt agar (Staphylococcus aureus), Mac Conkey Klebsiella pneumonia, Eosin Methylene Blue (Escherichia coli and Enterobacter aerogenes), Xylose Lysine Desoxycholate agar (Salmonella spp.) and in Shigella Salmonella agar (Shigella spp). There was no growth in cetrimide agar, a differential media for Pseudomonas spp. However this microbe was identified by API 20 E.

In addition, API $20 \mathrm{E}$ confirmed other bacterial isolates which included Chryseomonas luteola, Klebsiella oxytoca, Enterobacter cloacae, Serratia marsencens, Enterobacter agglomerulans and flavobacterium spp. (Table 3).

\begin{tabular}{|c|c|c|}
\hline Isolate & Numerical profile* & Identity \\
\hline AD226 & 3203000 & Chryseomonas luteola \\
\hline BP229 & 1047573 & Klebsiella oxytoca \\
\hline BP231 & 7305573 & Enterobacter cloacae \\
\hline KM002 & 5106720 & Serratia marsencens \\
\hline MH030 & 1247173 & $\begin{array}{c}\text { Enterobacter } \\
\text { agglomerulans }\end{array}$ \\
\hline MH033 & 1212004 & Flavobacterium spp. \\
\hline NE042 & 2212004 & $\begin{array}{c}\text { Pseudomonas } \\
\text { aeruginosa }\end{array}$ \\
\hline
\end{tabular}

*From biomeriux vitek, Inc[12].

Table 3: Numerical profiles of the microbes identified by API 20 E.

\section{Molecular Characterization Gel Analysis}

The visualization of the agarose gel after electrophoresis is shown in Figure 1. Six DNA bands of the unknown bacterial isolates were visualized in the agarose gel after electrophoresis (Figure1) $\mathrm{M}$ is the standard DNA molecular weight marker.

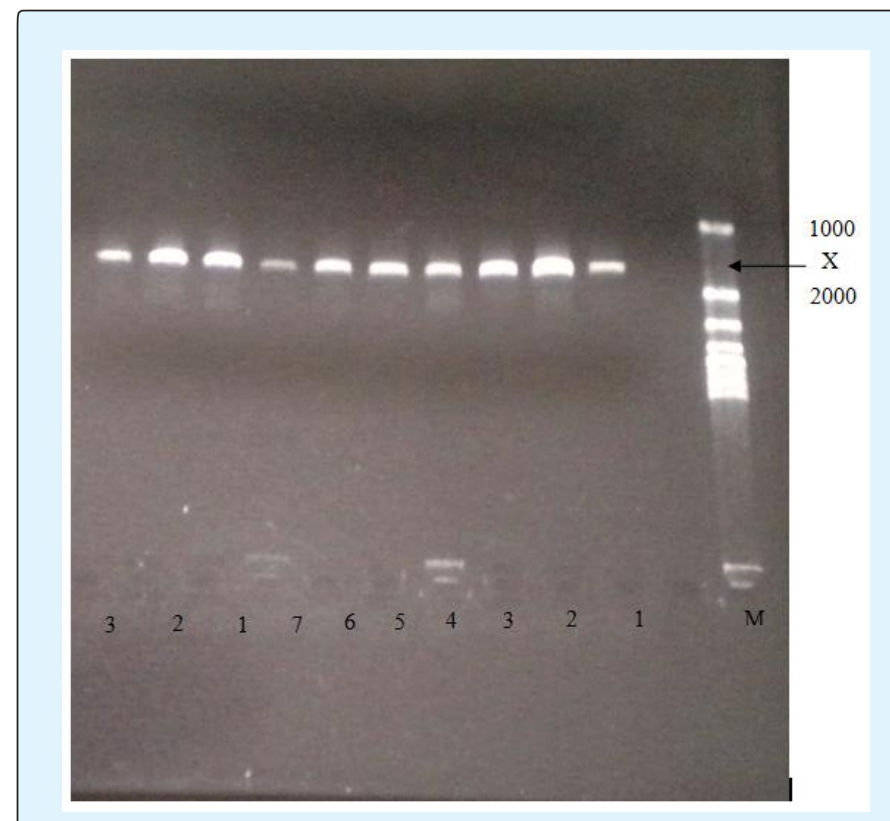

Figure 1: Agarose gel analysis of bacterial isolates DNA.

The unknown samples (1-6) were compared with the standard $1 \mathrm{~kb}$ ladder (M). As shown in the Figure $1, \mathrm{X}$ is approximately 1500 base pairs equivalent to the gene of interest (16SrDNA). These findings confirmed the presence of 16SrDNA gene estimated to be $1500 \mathrm{bp}$. Bacterial with similar sequences to the unknown samples analyzed are shown in Table 4.

\begin{tabular}{|c|c|c|c|}
\hline Sample ID & Contig No. & No. Bases & Identity \\
\hline MH029 & 1 & 1120 & Bacillus pumilus \\
\hline KM001 & 2 & 1470 & Kocuria rosea \\
\hline US201 & 4 & 1533 & Cronobacter sakazakii \\
\hline KM008 & 8 & 547 & Bacillus safensis \\
\hline KM013 & 9 & 1494 & Bacillus flexus \\
\hline CS168 & 11 & 1507 & Bacillus subtillis \\
\hline
\end{tabular}

Table 4: Identities of microbes with similar sequences to samples.

The phylogenetic tree illustrating phylogenetic relationships between unknown sample isolates and other bacteria is shown in Figure 2 and Figure 3 respectively. The nucleotide sequences of fragments obtained using primers F27 and R1492 annealing to the 16S rDNA of samples KM001 and US201 and their respective contigs are shown in appendix 1 . 


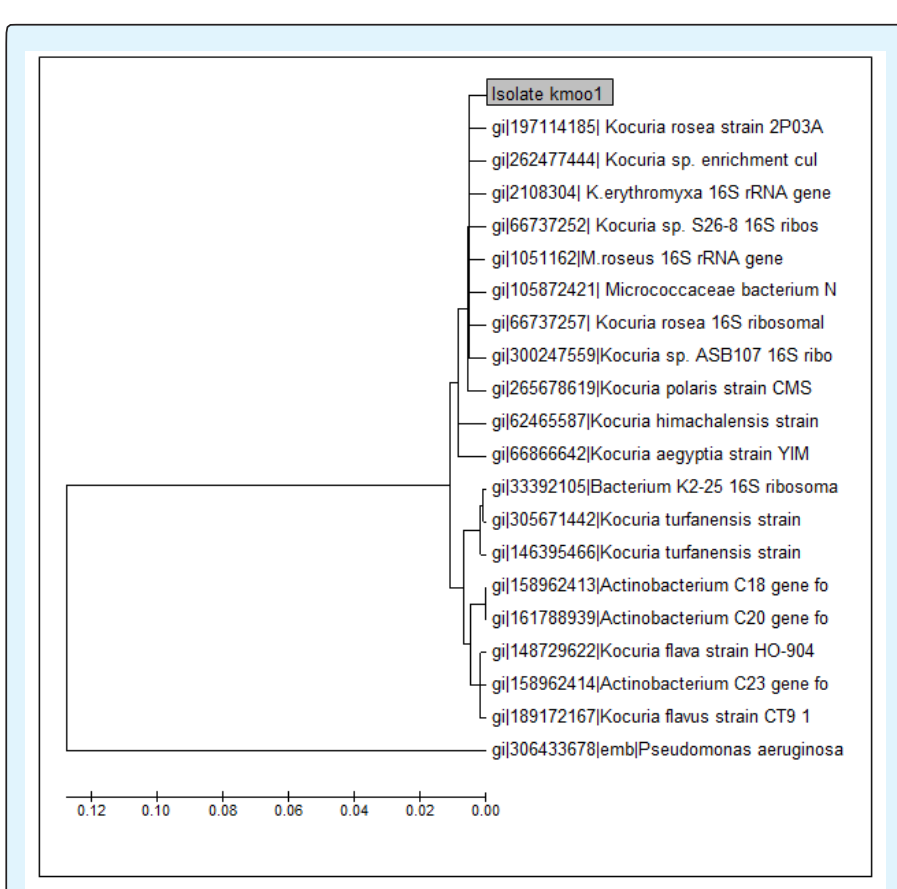

Figure 2: Phylogenetic tree of isolate KM001 based on 16SrRNA gene sequences.

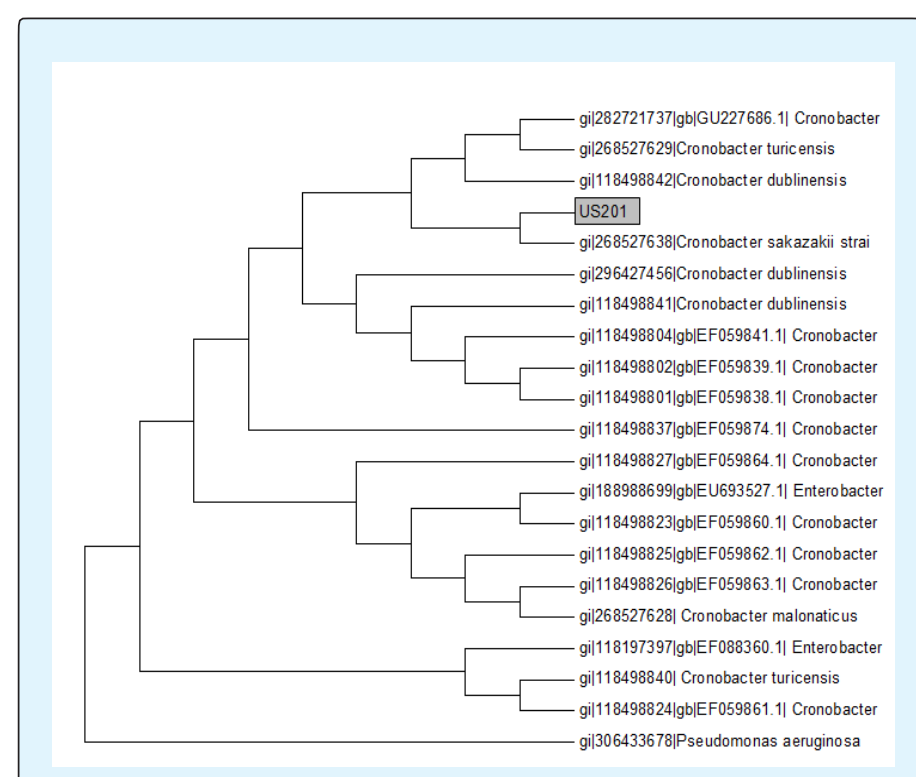

Figure 3: Phylogenetic tree of isolate US201 based on 16SrRNA gene sequence.

The phylogenetic trees were constructed using the neighbor joining method and Pseudomonas aeruginosa was used as an out-group.

\section{Discussion}

All the nineteen bacteria isolated from herbal products were identified by use of both traditional phenotypic and modern genotypic methods. The gram stain, an essential tool for classification and characterization of microorganisms was utilized in the study and formed the basis of isolating the 19 species of bacterial. The gram stain is the most important type of differential stain in bacteriology which divides bacterial cells into two major groups based on their cell difference [12]. Gram positive cells have a thick peptidoglycan layer while gram-negative ones have a much thinner one surrounded by outer lipid containing layers.

Selective media are used to isolate specific groups of bacteria by incorporating chemical substances that inhibit the growth of one type of bacteria while permitting the growth of another. Differential media distinguish among morphological and biochemically related groups of microbes by incorporating chemical compounds that on inoculation and incubation produce a characteristic change in the appearance of bacteria growth or the medium surrounding the colonies thus permit differentiation. MSA contains $7.5 \%$ sodium chloride which discourages the growth of competing organisms thus select growth of staphylococcus. The medium also contains a $\mathrm{PH}$ indicator that changes color if the mannitol in it is fermented to acid. $S$ aureus are therefore readily identified because they grow at high salt concentration and ferment mannitol to acid changing color to yellow. EMB is inhibitory to Grampositive bacteria. It also has the dyes Eosin and Methylene blue which differentiates between enteric lactose fermenters and non-fermenters. The coliform bacteria Enterobacter aerogenes produce thick mucoid pink colonies while E. coli appear blue black with a metallic green sheen caused by the large amount of acid produced which precipitates the dyes to the growth surface. MacConkey agar is both differential and selective. It contains bile salts and crystal violet which inhibited the growth of Gram-positive bacteria. Because it also contains lactose, Gram-negative bacteria that grew on this disaccharide were non-lactose fermenters since they were colorless. Lactose fermenters grow red or pink colonies hence Klebsiella pneumonia.

Biochemical characteristics play a major role for bacterial identification. They include enzymes (catalase, oxidase, decarboxylase), fermentation of sugars, capacity to digest or metabolize complex polymers and sensitivity to drugs. 
Others include hydrogen sulphide production, indole test, phenylalanine deaminase test, nitrate reduction and methyl red test. The study utilized Rapid test for biochemical identification. The API rapid Biochemical identification system was studied and evaluated by Michael, et al. [16] who found out that $94.9 \%$ of the microbes were correctly identified. Despite Michael et al terming the technique user friendly and accurate, in this study, the technique accurately identified thirteen species of bacteria, confirming presence of six which had been earlier identified and seven new ones (Table 3) which had not been characterized. The technique could not however identify six isolates. The current study corroborates with a study by Djokoto J, et al. [17] which termed phenotypic methods as not conclusive in microbial identification.

Sequencing of the 16SrRNA gene of six remaining unidentified isolates and the subsequent search for homology at the NCBI-BLAST database established their identities (Table 4). 16SrRNA gene is the most common sequence used for microbe identification [19]. Polymerase Chain Reactions are used to amplify the 16S rRNA gene before the sequence is determined, presence of the appropriate amplified PCR product confirmed the presence of the organism's DNA (Figure 2). The identification of microbes which otherwise would not be characterized phenotypically confirms the accuracy of the genotypic method in bacterial identification. The findings from this study agrees with another study by Yi-wei, et al. [20] that species which could not be identified by exhaustive phenotypic methods were identified genotypically hence his conclusion that sequence determination of 16SrRNA gene fragments represent a highly accurate and versatile method for the identification of bacteria to the species level even when the species in question is notoriously difficult to identify by biochemical means.

The phylogenetic analyses of isolate KM001's 16SrRNA gene sequences placed it within the genus Kocuria, the greatest sequence similarity being found with Kocuria rosea (Figure 3). Kocuria is a member of the micrococcaceae family. Though their role as human pathogens has not been clearly determined, Fevzi, et al. [20] reported that Kocuria rosea cause catheter related bacteremia in patients. This is the first time Kocuria rosea is reported as a contaminant in herbal medicines.

The phylogenetic analyses of the 16SrRNA gene sequences of isolate US201 has placed it within the genus Cronobacter with the greatest sequence similarity being found with Cronobacter sakazakii (Figure 3). This is a
Gram-negative non-sporing rod which is widespread in the environment. It has been linked to incidences of infant meningitis and necrotizing enterocolitis due to contaminated infant formula [21]. Its presence in herbal medicines can be attributed to poor handling. Isolates MH029, KM008, KM013 and CS168 were identified as genus Bacillus (Table 4). Bacillus organisms are common contaminants in the environment and majority of their bacteremia are not clinically significant. Bacillus pumilus has however been associated to a compound that has fungicidal activity against Aspergillus spp. [22]. Though many of the microbes reported in this study have been isolated from herbal medicines in the previous studies a few (Kocuria rosea, Cronobacter sakazakii, and Chryseomonas luteola are new and were isolated for the first time. The isolation of new unsuspected microbial contaminants from herbal products corroborates a warning in Nicole et al. [23] to practitioners and manufacturers of nonsterile pharmaceuticals on the awareness of possible contamination by other organisms not included in the USP.

\section{Conclusion and Recommendation}

Microscopic observations and Gram staining, showed that $68 \%$ of the bacteria were Gram-negative while $32 \%$ were Gram-positive. Through biochemical tests by differential, selective media and API 20 E profiling, 13 species of bacteria were identified. Of the total, 19 bacterial contaminants that were isolated and identified in the study, the traditional techniques failed to identify six species that were identified by genotypic technique. The study therefore showed that genotypic techniques appropriately applied could be used for accurate and routine microbial identification tests in herbal drugs and pharmaceutical manufacturing products. It is recommended that more screening of herbal medicines be done by genotypic methods to rule out chances of contaminants that may not be characterized through traditional methods.

\section{References}

1. WHO (1998) Quality control methods for medicinal plant materials, World Health Organization Geneva pp. $1-111$.

2. WHO (2013) World health organization traditional medicine strategy 2014-223.

3. WHO (2011) World health organization global status of noncommunicable diseases (NCDs). 
4. WHO (2004) WHO guidelines on safety monitoring of herbal medicines in Pharmacovigilance systems. World health organization Geneva 2004.

5. WHO (2007) World health organization guidelines for assessing quality of herbal medicines with reference to contaminants and residues.

6. Adenike O, Adewoyin A, Oluwatoyin A (2007) Evaluation of pharmaceutical and microbial qualities of some herbal medicinal products in South Western Nigeria. Tropical J of Pharmaceutical Research 6(1): 661-670.

7. Onyambu M, Thoithi GN, Ouya GO, Chepkwony HK, Osanjo G (2013) Microbial quality of unregulated herbal medicinal products in Kenya. African Journal of Pharmacology and Therapeutics 2(3): 70-75.

8. (2007) British Pharmacopoeia (BP) 2: A184-A192.

9. USP-NF (2009) The official compendia of Standards 1: 71-81.

10. (2003) International Pharmacopoeia.

11. Preston NW, Morrel A (1962) Reproducible Results with the Gram Stain. J Pathol Bacteriology 84(1): 241243.

12. Biomeriex Vitek, Inc, $20 \mathrm{E}$ analytical profile index, Enterobacteriaceae and other gram-negative bacteria, $10^{\text {th }}(\mathrm{Edn}$,$) .$

13. Hall TA (1999) Bioedith: User-friendly Biological sequence alignment editor and analysis program for windows 95/98/NT. Nucl Acids symp Ser 41: 95-98.

14. Edgar RC (2004) MUSCLE: Multiple sequence alignment with high accuracy and high throughput. Nucleic acids research 32 (5): 1792-1797.

15. Kumar S, Tamura K, Nei M (2004). MEGA 3: Integrated software for molecular evolutionary genetics analysis and sequence alignment. Briefings in Bioinformatics 5(2): 150-163.
16. Michael J Miller, Peter Alachi (1996) Evaluation of new computer enhanced identification program for microorganisms. Journal of clini Microbial 34(1): 179181.

17. Djokoto Kisworo, Elegado FB, Virginia LB (2008) Phenotypic and Genotypic characterization of Probiotic dairy products in the Philippine. Philippine Journal of Science 137(1): 77-83.

18. Drancourt M, Claude B, Antoine C, Rolland M, JeanPierre G, et al. (2000) 16Sribosomal DNA sequence analysis of a large collection of environmental and clinical unidentifiable bacterial isolates. J Clin Microbiol 38(10): 3623-3630.

19. Tang YW, Ellis NM, Hopkins MK, Smith DH, Dodge DE, et al. (1998) Comparison of Phenotypic and Genotypic Techniques for Identification of unusual aerobic pathogenic gram-negative bacilli. Journal of Clinical Microbiology 36(12): 3674-3679.

20. Fevzi A, Orhan Y, Bulent E, Gundogan B, Sumerkan B, et al. (2004) Catheter-related bacteremia due to Kocuria rosea in a patient undergoing peripheral blood stem cell transplantation. BMC infectious diseases (4): 62.

21. Iversen C, Lehner A, Mullane N, Bidlas E, Cleenwerck I, et al. (2007) The taxonomy of Enterobacter sakazakii: Proposal of a new genus Cronobacter. BMC Evolutionary Biology 7(64): 1471-2148.

22. Edward JB, Richard WP (2003) Production by Bacillus pumilus of an anti-fungal compound that is active against Mucoraceae and Aspergillus species. Preliminary report Med Microbiol 52(1): 69-74.

23. Nicole VU, Thomas BS (2014) Quality control: Microbial limit tests for Nonsterile Pharmaceuticals part 2. Journal of Pharmaceutical compounding 18(4): 305-310. 